\title{
Reliance on the internal auditors' work: experiences of Swedish external auditors
}

\author{
Daniela Argento ${ }^{1} \cdot$ Timurs Umans $^{1,2}$ (D) - Patricia Håkansson ${ }^{1}$. \\ Annika Johansson ${ }^{1}$
}

Published online: 18 December 2018

(c) The Author(s) 2018

\begin{abstract}
The purpose of this study is to explore how external auditors experience their decision to rely on internal auditors' work. This study employs both qualitative and quantitative methods consisting of semi-structured interviews and questionnaires administered to external auditors in Sweden. Semi-structured interviews were conducted with external auditors who are working in Big 4 audit firms in Sweden and have engagements with internal audit functions. A questionnaire was administered to authorized/approved auditors, members of the Swedish Association of Certified Public Accountants (FAR). Findings indicate that external auditors use the work of internal auditors as they gain efficiency in performing their work. Nevertheless, external auditors may compromise their independence and professionalism through closer involvement with internal auditors, which may lead to uncritical evaluation and use of the reports prepared by internal auditors. At the same time, while relying on the internal auditors' reports, external auditors appear to be conscious of the consequences for the audit quality they deliver. The study highlights the dilemma faced by external auditors in their cooperative work with internal auditors and the balance/imbalance in their opinions concerning efficiency gains, independence, professionalism and audit quality.
\end{abstract}

\footnotetext{
Daniela Argento

daniela.argento@hkr.se

$\bowtie$ Timurs Umans

timurs.umans@hkr.se

Patricia Håkansson

patriciahakansson@hotmail.com

Annika Johansson

annika.johansson3@hotmail.com

1 Department of Business Administration, School of Business, Kristianstad University, Kristianstad, Sweden

2 Department of Management Control and Logistics, School of Business and Economics, Linnaeus University, Växjö, Sweden
} 
Keywords Auditing - Audit quality - Cooperation - External audit · Internal audit · Reliance $\cdot$ Sweden

\section{Mathematics Subject Classification M40}

\section{Introduction}

External auditors' (EAs) reliance on the work of internal auditors (IAs) has gained heightened attention in recent years (Brody 2012; Desai et al. 2017; Munro and Stewart 2011; Pike et al. 2016). The increased presence of the Internal Audit Function (IAF) generates opportunities for EAs to cooperate with IAs (Mihret 2014; Munro and Stewart 2011). The International Standard of Auditing (ISA) 610 states that the work of the IAF can be used by EAs to obtain audit evidence. In addition, IAs can be used to provide direct assistance when working under an EA's direction, supervision and review (ISA 610 2013). Since the work of EAs and IAs overlaps to some degree, they have some interests in common and both can potentially benefit from successful cooperation (Brody 2012; Morrill and Morrill 2003; Suwaidan and Qasim 2010). EAs that rely on and use the work of IAs can gain efficiency by reducing the amount of audit work they need to do. The IAF, with adequate competence, objectivity and work performance, can contribute to an effective external audit process (Al-Twaijry et al. 2004). The latter argument would indicate that IAs could gain status and in turn legitimize the growing importance of the IAFs as a key component of corporate governance (Chen et al. 2017).

However, cooperation between EAs and IAs has been assumed to be something of a double-edged sword. On one hand, EAs' reliance on and use of IAs' work can lead to efficiency improvements by eliminating the duplication of work (Morrill and Morrill 2003; Suwaidan and Qasim 2010), thus reducing the costs of the external audit and the respective audit fees (Chen et al. 2017). On the other hand, close cooperation between EAs and IAs can influence the quality of the external audit (Abbott et al. 2012; Pizzini et al. 2015; Lin et al. 2011). IAs deemed by EAs as not sufficiently professional and independent (Al-Twaijry et al. 2004) might discourage cooperation due to EAs' perception of potential threats to the external audit quality. An EA's decision to rely on and use the work of the IA can produce potential economic consequences and implications for external audit efficiency and quality (Glover et al. 2008; Pizzini et al. 2015).

Therefore, in deciding whether or not to rely on and use the work of IAs, EAs are faced with a number of complex decisions (Brody 2012). They need to keep in mind the purpose of the external audit, that is, the provision of timely and accurate information to the stakeholders and the society overall (Duska 2005; Tagesson and Eriksson 2011), while responding to pressures to cooperate more with the IAF. Such pressures may come from clients and standard setters. For instance, the Public Companies Accounting Oversight Board (PCAOB) recommended a reduction of audit costs through the EAs relying on the work of IAs (Brody 2012; Chen et al. 2017).

While the empirical dilemma is acknowledged (Swanger and Chewning 2001), there is a need for more research on the degree of EAs' reliance on the work of IAs (see 
Desai et al. 2017). In addition, there appears to be 'a paucity of research concerning the effects of EAs' reliance on IAF in terms of external audit quality' (Bame-Aldred et al. 2013, p. 253)., The aim of this paper is to address this void by exploring how EAs experience their decision to rely on IAs' work. The emphasis is on the perception of EAs in particular since that decision is formally invested with the EAs (ISA 610 2013).

This explorative study is conducted in Sweden, motivated by the fact that the performance of internal auditing is stipulated in a number of contexts such as the Swedish Stock Listed Corporations (Swedish Corporate Governance Board 2010), financial institutions under the supervision of the Swedish Financial Supervisory Authority (FAR 2013), and governmental agencies, positioned under the government (SFS 2006:1228 2\$), bodies that are often also required to have an external audit. Further, Sweden represents an interesting empirical context given the high degree of trust that exists in the Swedish society (Rothstein and Uslaner 2005), which increases not only the probability of cooperation between EAs and IAs but also the reliance on and use of IAs' work by EAs.

The main contribution of the paper lies in understanding of how EAs experience their decision to rely on IAs' work in relation to their perceived professionalism, independence and audit quality as well as in understanding the motives underlying the use of IAs' work. The study contributes further by using both qualitative and quantitative methods to explore these relationships. The qualitative part of the study highlights both the pros and cons of EAs deciding to rely on IAs' work, as well as the perceived outcomes of the cooperation between the parties. Building on these findings, the quantitative part of the study further explores the relationship between those pros and cons and perceived cooperation outcomes.

The remainder of this paper is structured as follows: the next part presents the theoretical framework guiding the study and is followed by the methods, results and analysis sections. The paper then presents conclusions and suggestions for future research.

\section{Theoretical framework}

When cooperating with IAs, EAs could face a number of dilemmas (Bame-Aldred et al. 2013). EAs must, according to ISA 610 (2013), make some judgments-in other words, decisions-before and during the cooperation with IAs. The decision to rely on and use the work of the IA is critical as it could compromise the external audit quality (Al-Twaijry et al. 2004; Glover et al. 2008; Morrill and Morrill 2003; Suwaidan and Qasim 2010). Several aspects may simultaneously influence EAs when they are deciding whether to cooperate with IAs.

\subsection{EAs' independence and professionalism}

EAs are hired and paid by their clients (i.e. the auditees) to execute an external audit. Despite this direct relationship, EAs need to serve a wider scope and be independent 
from their clients and act professionally in their audit work. According to Chrystelle (2006), the EA is a link between an organization and its stakeholders. Independence is an integral part of the auditor's role and purpose and is a fundamental guiding principle within the auditing profession (Duska 2005; Jeppesen 1998). EAs' independence and professionalism are seen as essential elements to ensure audit quality (Knechel et al. 2013; Francis 2011; Grey 1998).

Compromising independence is seen as detrimental both to the auditing profession, which could lose public confidence and viability (Arya and Glover 2014; Carrington 2010), and to the users of the audit reports, who would be unable to trust the information provided (Jeppesen 1998). This independence can be threatened if the EA unconsciously, or consciously, favours the interest of the auditee (i.e. the client). Clients that make substantial investments in their IAF view cooperation between EAs and IAs positively. An increased reliance on the work of the IA would decrease the amount of work performed by the EA, resulting in lower external audit fees (Brody 2012).

In line with the arguments of agency theory, human behaviour is guided by the desire to maximize self-interest (Jensen and Meckling 1976; Ross 1973). Jeremy Bentham in the $1800 \mathrm{~s}$ (in Edwards 1954, p. 382) claimed that the goal of human action is to seek pleasure and avoid pain. Therefore, EAs might make decisions in a rational way, seeking to maximize their own benefit (self-interest) or considering the best alternative to be the one with the largest margin between benefits and costs (Edwards 1954; Etzioni 2014; Jonassen 2012). EAs could act in self-interest and use the IAs' work, even if it is not appropriate, in order to please the client and/or to improve efficiency of the audit task, thereby prioritizing their own interests over ensuring the highest quality audit for stakeholders and the society. There is a risk that the agent (i.e. the EA deciding whether and to what extent they should to rely on IA work) will not always act in the best interest of the principals (i.e. the auditee, stakeholders and society).

The work style of the EAs plays an important role in this situation and may influence how they apply professional judgment and make subsequent decisions as to how the cooperation should proceed and where its boundaries lie (see Brody 2012). Professional knowledge and strength of professional identity determine how strategic decisions about cooperation are made and provide guidance to the EA in maintaining independence (Steptoe-Warren et al. 2011).

\subsection{Professional standards and regulations}

ISA 610 (2013) allows cooperation among EAs and IAs, either by the EA using the IAF's work as audit evidence or using the IA's direct assistance. To ensure that the purpose of the external audit is not adversely affected by the cooperation, ISA 610 (2013) defines the requirements that the EA must take into account and apply while determining whether, in which areas, and to what extent the work of IAs can be used. Even if an EA chooses to use the work of IAs, the EA still has the sole responsibility for the audit (ISA 610 11§, 2013). According to ISA 610 (2013), the EA, in deciding whether to use the work of IAs, has to establish the overall audit strategy. In this way, ISA 160 (2013) emphasizes the importance of planning before making the decision 
about whether and how to use the IA's work. According to ISA 315 (2013), the planning includes the EA's evaluation of the IA's work in order to determine the relevance of the internal audit for the EA's assignment. Further, ISA 200 (2009) stipulates that, before making the final decision, the EA should consider its implications for the performance of an independent audit and, by default, its implications for audit quality.

\subsection{The evaluation of IAs' independence, professionalism and quality}

The decision to cooperate with IAs formally depends on the EAs' judgment of the IAs' work, professionalism and independence (Chen et al. 2017; Desai et al. 2017; Pizzini et al. 2015). While IAs consider themselves to belong to the profession and to possess the required competence (IIA 2018a, b), both theorists and practitioners appear to question this assumption (Al-Twaijry et al. 2004; Allegrini et al. 2006). The resources devoted to the IAF are often limited, and thus IAs do not always have the level of independence and competence that would allow EAs to feel confident relying on the IAFs. It is also claimed that the double role of the IAF, as both consultant and part of the corporate governance mechanism (Stewart and Subramaniam 2010), compromises its independence from the organization where the IA is employed (Arnold et al. 2013). EAs often hold the opinion that IAs do not possess sufficient competence, professionalism and independence from management (Al-Twaijry et al. 2004; Roussy and Brivot 2016). For example, when IAs receive incentive-based compensation linked to company performance, EAs are inclined to evaluate their objectivity negatively and are thus less likely to rely on their work. Because of EAs' increased effort in such circumstances, the external audit fees can be higher (Chen et al. 2017). Glover et al. (2008) found that EAs are more positive towards outsourced IAFs compared to in-house IAFs ${ }^{1}$ and Chen et al. (2017) report that external audit fees are lower in cases where EAs cooperate with outsourced IAs than they are when cooperating with in-house IAs.

The evaluation of and reliance on the IAF becomes critical when the work of the IA is perceived by the EA to be subjective and thus more susceptible to bias (Glover et al. 2008). Therefore, when the quality of the IAF is questioned and not trusted, using the work of IAs can potentially compromise the quality of the audit performed by the EA (Morrill and Morrill 2003; Lin et al. 2011; Pizzini et al. 2015).

\subsection{Interactive work process}

Reliance on someone else's work entails mutual trust, understanding, and lower transaction costs (Bachmann and Inkpen 2011; Tomkins 2001). Vangen and Huxham (2003) argue that building trust is a complex and cyclical process which often develops through positive experiences and outcomes of cooperation between the parties. Therefore, cooperation between EAs and IAs has to be continuously nurtured in order to create the advantage desired by both parties. In addition, the frequency of interactions and type of communication between these two parties may increase trust. Mayer et al.

\footnotetext{
1 Outsourced IA refers to a person/firm that is hired by the auditee to execute the internal auditing function, but is not formally employed by the auditee.
} 
(1995) stress that trust is built on 'a decision which is based on an assessment of the other party's competence, integrity and benevolence' (p. 284). Development of trust over time through interaction could lead to the IA being perceived as objective and competent by the EA. This may result in greater use of the IA's work and less rigour on the part of the EA in checking that work.

There is a possibility that an EA could make decisions that are not fully rational but are instead based on personal relationships that involve emotions, experiences and personal identity (Jonassen 2012). Cooperation between EAs and IAs consists of human involvement, and an EA could decide to rely on and use the work of IAs because of the personal relationship that might have already developed (in past cases) between them after prolonged and successful cooperation (Brody 2012). In both cases, there could be an effect on audit quality as the EA could use the work of IAs even if it is not appropriate to do so.

\subsection{Cooperation outcomes}

The idea behind cooperation is to gain a mutual advantage, which is often achieved by sharing resources and information (Delbufalo 2012; Vangen and Huxham 2003). One of the outcomes of cooperation between EAs and IAs is the efficiency gain obtained by avoiding work duplication, with a consequent reduction of external audit fees (Morrill and Morrill 2003; Pike et al. 2016; Suwaidan and Qasim 2010). There is evidence indicating that the greater the cooperation (i.e. the greater the contribution of the IA's work), the lower the external audit fee (Felix et al. 2001; Mohamed et al. 2012). As another advantage of good cooperation, Lin et al. (2011) argue that EAs are more likely to detect material weaknesses when they rely on the work of the IAF. Efficiency gains and reduction of audit fees are advantages often emphasized by both auditees and the audit firms (Duska 2005; Felix et al. 2001). Auditees favour reduction of audit costs since it often fits into the discourse on cost reduction under which many firms operate; for the EAs, reduction of their fees could allow them to compete with other actors on the market and potentially lead to competitive advantage (Broberg et al. 2013). This might indicate that even though cooperation may result in their earning lower fees, audit firms might be interested in cooperation between EAs and IAs in order to keep their clients.

Despite such potential positive outcomes, there are some side effects of cooperation. Svanberg and Öhman (2013) stress that auditors working in the Big 4 are subject to great working pressure because of the competition in the auditing industry. In addition, the fact that audit firms allocate a specific number of hours for the execution of audit tasks (in order to control the costs of auditing) generates time pressure, which has 'a detrimental impact on individuals' decision-making processes' (Gundry and Liyanarachchi 2007, p. 129). EAs who are exposed to high pressure might feel stress, which can affect the audit quality negatively (Broberg et al. 2017; Gundry and Liyanarachchi 2007; McNamara and Liyanarachchi 2008; Svanberg and Öhman 2013). Thus, the opportunity to reduce time spent on audits and lessen overall pressure could be another reason why EAs are more likely to cooperate with IAs and use their work in the audit process (Brody 2012). Indeed, Desai et al. (2017) found that even when 


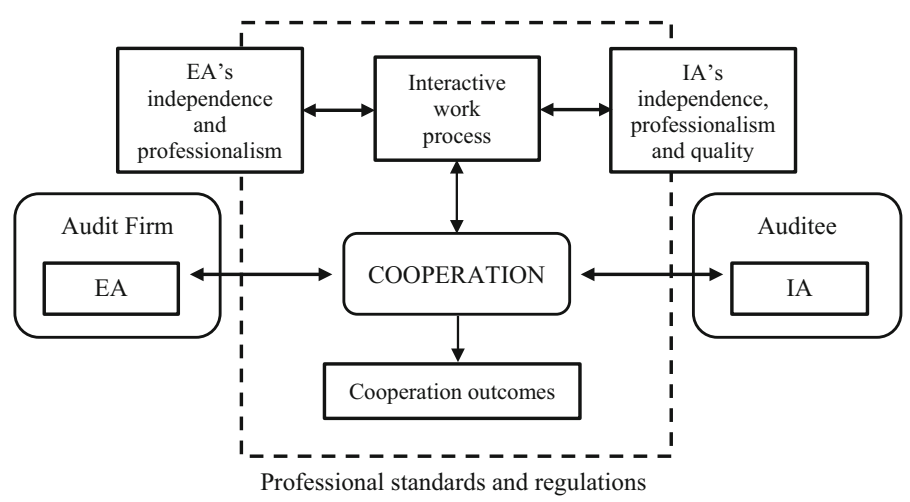

Fig. 1 Theoretical Framework

judgments about IAs' work, competence and objectivity are all negative, EAs may still choose to rely on the IAs' work. This behaviour might be dangerous in the long run and expose EAs to enhanced legal liability (Brody 2012).

The theoretical framework (see Fig. 1) includes the various aspects that EAs might simultaneously take into account in their decision to cooperate with IAs. In particular, an EA's decision to use the work of IAs may be influenced by the awareness of their own obligation to continuously preserve their independence and professionalism with regard to the aim of ensuring audit quality. The professional standards and overall regulations could also play a role in the cooperation because of their requirements concerning the evaluation of the IAF. The EAs might have their own opinions about IAs' independence, professionalism and quality that could influence the decision to start or continue the cooperation. Furthermore, frequency of interaction, type of communication and emergence of trust could each play a role in determining how the cooperative process actually works. Finally, the cooperation may lead to both positive and negative outcomes. The cooperation could lead to efficiency gains in terms of time and cost savings, but it could also compromise the quality of the external audit, and the overall effectiveness of the external audit process may be lost if the cooperation is not functioning optimally.

\section{Research design}

In order to satisfy the aim of this paper we adopted a research design that includes both qualitative and quantitative data and analyses. Such choice was deemed particularly appropriate given the complexity of the framework, where both the processes and the outcomes of cooperation were to be explored. First the qualitative part is presented, followed by the quantitative part inspired by the findings of the qualitative part. The theoretical framework developed in the previous section serves as the analytical prism through which the empirical findings of both parts are interpreted. Afterwards, the overall findings are discussed in the final section of the paper. 


\subsection{Research method: qualitative study}

The qualitative study consisted of eight semi-structured interviews (Thomas 2004) aimed at obtaining an understanding of the aspects EAs consider relevant in their cooperation with IAs (see "Appendix 1"). Using interviews as a data collection technique was deemed appropriate given the explorative nature of the study and the aim of exploring how EAs experience their decision to cooperate with IAs (cf. Arena and Azzone 2009). Because of this aim, the interview questions were only loosely informed by the theoretical framework presented in Fig. 1. In line with Harvey (2011), every respondent was asked to answer each question but was also allowed to speak freely and give additional opinions or explanations that could expand the theoretical framework developed in Fig. 1. As argued by Denscombe (2009), semi-structured interviews are a suitable tool for investigating EAs' opinions, perceptions, feelings, and experiences in connection with sensitive topics such as audit quality.

Interviewees were selected in accordance with the following criteria to ensure procedural reliability (Ryan et al. 2002). The EAs were required to have audit engagements with clients that had IAFs; they were to be a part of the team that interacted with the IA and to be the signing auditor. Eight respondents, all working in one of the Big 4 in Sweden, were interviewed in May 2014 (Håkansson and Johansson 2014). Four of the respondents have primarily financial institutions as clients and the other four work with listed companies that do not operate in the financial sector. Three interviews were conducted face-to-face, and the other five were conducted by telephone to overcome geographic restrictions. All interviews were conducted in Swedish (the native language of all the respondents and interviewers) by two of the authors of this paper. The fact that the interviews were conducted by different means could be an issue, given that facial expressions and non-verbal language could be beneficial for interpretation and were not observable in the phone interviews. Thus, when analysing the findings the authors have tried to be aware of the different interview means and checked whether interpretations varied; no differences associated with this were detected. All interviews lasted between 25 and $60 \mathrm{~min}$ and were recorded and transcribed. In this paper, each EA has been identified with a code (EA1-EA8) to ensure anonymity. Table 1 presents the respondents with reference to professional tenure, audit firm, office size, use of IAs' work and type of interview.

The number of interviews does not allow for strong generalizations (Soh and Martinov-Bennie 2011; Thomas and Magilvy 2011). Even if the eight interviews do not make it possible to claim saturation, which is generally achieved after 12 interviews (Guest et al. 2006), this part of the study still provides some insights by developing the themes that are usually achievable after six interviews (Arena and Azzone 2009).

When the interview transcripts were analysed, the answers given by each respondent were compared to identify similarities and differences. If some emerging themes were unclear, or confirmations were necessary, respondents were contacted for supplementary or clarifying information, thereby increasing the validity of the data. Finally, interpretations and conclusions were made through constant iteration with the theoretical framework. 
Table 1 Interview respondents

\begin{tabular}{llllll}
\hline Respondent & $\begin{array}{l}\text { Professional } \\
\text { tenure (years) }\end{array}$ & Audit firm & Office size & $\begin{array}{l}\text { Use of IAs' } \\
\text { work }\end{array}$ & $\begin{array}{l}\text { Types of } \\
\text { inteviews }\end{array}$ \\
\hline EA1 & 35 & KPMG & Midsize & Medium use & Face-to-face \\
EA2 & 24 & EY & Large & Extensive use & Face-to-face \\
EA3 & 17 & Deloitte & Large & Extensive use & Face-to-face \\
EA4 & 11 & PWC & Midsize & Limited use & By phone \\
EA5 & 20 & KPMG & Midsize & Limited use & By phone \\
EA6 & 25 & EY & Large & Limited use & By phone \\
EA7 & 15 & PWC & Large & Limited use & By phone \\
EA8 & 20 & KPMG & Large & Extensive use & By phone \\
\hline
\end{tabular}

\subsection{Results and analysis: qualitative study}

The interviews revealed that cooperation can take different forms. Some EAs cooperate with IAs through information exchange, which allows them to have better insight into the client's activity. For other EAs, the cooperation goes further as they use the IA's work when executing the external audit tasks. The parts of the IA's work that are deemed relevant and are used for the external audit typically consist of the material that concerns internal control and processes. None of the interviewed EAs used IAs to provide direct assistance. Each of the EAs stated that the degree of cooperation depends on the nature of the client. The four respondents (EA1, EA3, EA5 and EA8) who had experience with clients in the financial sector must follow particular industryspecific rules, namely, the obligation of the EA to evaluate the IAF even if that work will not be used for the external audit.

The responding EAs stated that a discussion between them and the IAs usually starts at the very beginning of the audit planning phase. During that phase EAs decide whether to cooperate with IAs or not. This reflects the ISA 610 (2013) stipulation that the EA has to establish the overall audit strategy and plan before deciding whether to use the IA's work. Our findings indicate that EAs embrace their role as strategic decision makers by thinking about and planning their involvement with IAs and considering the consequences of that involvement (Steptoe-Warren et al. 2011). The EAs stressed that the initiative to cooperate came mostly from their side, yet they also stressed the importance of mutual discussion. Communication between EAs and IAs usually took place by telephone, personal meetings and email, and the extent and type of communication varied depending on the engagement's size and the form of cooperation. Generally, our data indicate that the degree of contact between EAs and IAs could vary from as seldom as once per year to as often as once per week, depending on how the cooperation is organized. This is in line with the findings by Brody (2012) arguing that good interactions between EAs and IAs are a necessary condition to achieve good cooperation. 


\subsubsection{The evaluation of the IAF}

All the EAs mentioned ISA when discussing the evaluation of the IAF and its work. EA4 and EA5, working in two different audit firms, mentioned that their firm has interpreted the standard and drafted its own checklist based on it. This checklist has to be followed in the evaluation before deciding whether to use the IA's work. However, even if there is a standard concerning the cooperation between EAs and IAs, it is the respondents' opinion that the professional judgment of the EAs is of great importance when evaluating IAs' work. This finding supports the argument by Knechel et al. (2013), Francis (2011) and Grey (1998) that professionals possess specific knowledge that should be used to perform their work. EA7 argued that if using the work of the IAF:

One should not downplay the fact that it makes tremendous demands. You must see that they [the IAs] are objective, that they are competent. If one is to rely on an IA's work, then you need to do all that and ensure that they have done the task right.

This indicates that there are high requirements on the EA when doing the evaluation (Chen et al. 2017; Desai et al. 2017; Pizzini et al. 2015). However, one of the respondent's statements about the time required to evaluate the work of the IAF is quite interesting:

I just have to take one hour to say I trust the internal audit, its work, and have assessed its competence and quality. I can get an idea of what they write in their reports. And then I just sign off the internal audit's reports, in the section that concerns my work, and say that the internal audit considers the internal control as satisfactory and I consider it to be also.

This quote shows that the work style can also influence how EAs decide whether to rely on and use the work of IAs (Brody 2012). The respondents claimed that the evaluation of the IA's independence was based on where the IAF was located in the organization, whom the IA reported to, and whether there were any incentive systems, corroborating the arguments of Chen et al. (2017). EA4 admitted that it was difficult to evaluate the IA's objectivity and said that in the evaluation of the IAF he controlled how the work was performed and what conclusion the IA had drawn, and he checked whether he would have come to the same conclusion. As for the evaluation of IAs' competence (i.e. professionalism), the EAs stated that this evaluation was based on the IA's education and experience. EA1 added that the competence of the IA would be apparent once the EA had worked with him/her. Thus that EA seemed to follow his/her feelings, which is in line with Jonassen (2012), who states that emotions and experiences could have an impact on the decision making.

When asked if the evaluation resulted in more or less work for the EA in the audit process, five respondents clearly stated that the total time would decrease if the IA's work was assessed to be useful. Such positive evaluation leads to efficiency improvements for the EAs. However, the situation differs for the EAs working with financial institutions. EA3 explained that when working with financial institutions there was no difference in time, because the evaluation of the IAF and its work is 
part of the engagement: 'There must be a communication with financial companies, because it is part of my mission to check what the IAF does and how its function is designed'. Since this obligation exists, it might be tempting for the EA to make use of the IA's work when the evaluation has to be performed anyway, which would suggest that the EA is a rational decision maker (see Edwards 1954; Jonassen 2012). Overall, EAs execute the evaluation in accordance with ISA 610, but this guidance can be interpreted differently and is largely a matter of the EAs' professional judgment. It also seems that IAs' independence is harder to evaluate than their professionalism (i.e. competence). Finally, respondents confirmed previous findings from the literature (see Chen et al. 2017; Glover et al. 2008) as outsourced IAFs were deemed more objective than in-house IAFs.

\subsubsection{EAs' experiences of IAs' independence, professionalism and quality}

In general, the EAs had a positive attitude towards the establishment of IAFs within their clients. Some highlighted that IAFs are a good corporate governance and control mechanism, therefore agreeing with Mihret and Admassu (2011) and Soh and Martinov-Bennie (2011).

Other respondents emphasized that competent IAFs were good for the EA's work. EA1 stated:

Many times they [IAs] are at the forefront of what is about to happen and what has happened and what is going on and they see risks. So, it is an incredible support to the general audit of the business to have a competent internal audit, absolutely.

The fact that the auditee has good internal control results in the EA saving time on the audit because it indicates orderliness in the auditee. Otherwise, 'the controls on the company may become worse and then we would have to do more' (EA7). This quote shows how EAs appreciate the efficiency gains stemming from good cooperation with IAs, something that is already recognized in the literature (Brody 2012; Pike et al. 2016).

However, the respondents also stated that the IA was not as controlled as the EA and did not have the same requirements, which means that the quality of the internal audit did not reach the same level as the external audit. This opinion is in line with previous findings by Roussy and Brivot (2016) and Allegrini et al. (2006). One reason for lower quality is related to the argument that the IA is not as independent as the EA (Arnold et al. 2013; Al-Twaijry et al. 2004; Glover et al. 2008; Stewart and Subramaniam 2010). Four respondents distinctly pointed out that the IAs were not independent. Specifically, EA5 argued that the IA was working for only one stakeholder, while EA1 pointed out that the IAF was an extension of the Board, and therefore IAs could not be considered independent. Still, the existence of an audit committee may, as highlighted by EA6 and EA7, spread the perception that IAs are more independent, confirming the arguments by Roussy and Brivot (2016).

According to some respondents, the independence of the IAs depended also on the size of the IAF. If a company does not have sufficient resources for its IAF, independence and competence of IAs can be problematic and, in turn, can affect 
the likelihood that the EA will decide to use their work, corroborating the findings by Al-Twaijry et al.'s (2004). Contradicting this, however, EA4 declared that the size of the IAF was not important, in the sense that the competence and work of the IAs is of greater significance.

Building on these findings, it appears that respondents showed an awareness of the constraints in using the IAF's work. IAs are seen as not sufficiently independent and competent, and focused on different things than the EAs (Pike et al. 2016; Roussy and Brivot 2016). That is, IAs work for the Board and have other tasks that the EA may perceive as too narrow and specific (see Al-Twaijry et al. 2004; Arnold et al. 2013). EA6 and EA7 claimed that the IAs' work was not reliable because they were either doing the wrong things or doing the right things wrong; therefore, one could not always use the IA's work, for example, just to avoid duplication of work. One respondent stated that sometimes EAs had to check the work that had already been done by IAs. In such cases, the external audit process does not make efficiency gains but, instead, its overall effectiveness decreases (Brody 2012). In such circumstances, the EA had to 'explain that if we are to rely on what you are doing, you must test according to our rules [...] And it is not always the case [...]. You are usually much freer being an IA' (EA7).

Two respondents pointed at the advantages of outsourcing the IAFs (i.e. increased competence and legitimacy) that are also recognized in literature (see Glover et al. 2008; Roussy and Brivot 2016). Regarding IAs working in-house (i.e. within the auditee), EA1 said that 'being in one place and sitting at the coffee table and talking, and being at the same staff parties with those you later audit and evaluate-I think that almost seems impossible'.

In summary, the existence of an IAF in an organization can be positive for both the auditee and the EA as it usually leads to fewer inaccuracies in the organization. At the same time, the IAs are not perceived as independent and professional by the EAs, meaning, as Al-Twaijry et al. (2004) and Morrill and Morrill (2003) argue, that the work of IAs cannot be used to an unlimited extent by EAs since this could have a negative impact on audit quality.

\subsubsection{Interactive work process}

The theoretical framework suggests that the way cooperation evolves over time is linked to feelings of trust (Bachmann and Inkpen 2011; Tomkins 2001; Vangen and Huxham 2003). Half of the EAs thought that their communication with the IAs affected their trust in them. As an example, EA3 expressed it this way:

It depends of course on what the communication contains [...] but you can put it like this, if in my external audit I intend to rely in any way on what the IAF does, it is more likely that I will trust someone that I have a higher degree of cooperation and exchange with than someone I meet more rarely or communicate with more rarely. 
This quote corroborates the arguments by Brody (2012), who claims that good communication may engender greater trust. Half of the respondents stated that even the length and the type of communication influenced the EAs' usage of the IAs' work. The longer there had been cooperation and the EAs knew that the IAs were competent, the more they felt that they could rely on the IAs' work. This finding supports Bachmann and Inkpen (2011) in that trust is based, among other things, on the counterpart's competence. Other respondents were of the opposite opinion and claimed that the length and the type of communication do not affect the cooperation: 'It is not as if you have been working together for three years, then suddenly you start to work more together' (EA3).

In addition, emotions, experience and personal identity can be considered when making decisions (Jonassen 2012). Some EAs thought that personal chemistry was important in the cooperation with IAs while others did not. Most of them seemed to think that it made the cooperation work more smoothly but was not a crucial aspect in the decision to cooperate with IAs and to use their work.

In summary, the extent and type of communication seems to influence some of the EAs' trust in the IAs. A tentative interpretation is that a long-lasting and wellfunctioning cooperation sometimes leads to greater trust, as Vangen and Huxham (2003) argue, or in other words, to a greater use of IAs' work by EAs. At the same time, the EAs stated that they made the evaluation yearly, which would imply that the EAs tried to maintain their professional judgment so that the audit would not be negatively affected by a long cooperation. While the EAs did not seem to cooperate with IAs merely because of a favourable evaluation in terms of social matters, there was still some room for emotions and experience.

\subsubsection{Purpose and outcomes of cooperation}

A number of our respondents agreed that the purpose of their cooperation with an IA was to gain different types of benefits, which is also in line with findings by Etzioni (2014), Delbufalo (2012) and Vangen and Huxham (2003). One of our respondents stated: 'I prefer to take advantage of the IAs' work. If they do good work, I can benefit from it in some way' (EA4).

Our findings are in line with those of Brody (2012), Morrill and Morrill (2003) and Suwaidan and Qasim (2010) as the responding EAs indicated that cooperation with IAs leads to efficiency improvements. These gains, which appear to be interrelated, are manifested in reduction of work due to avoidance of duplication, time savings and/or cost savings.

Some respondents also claimed that the auditees were cost-conscious and wanted cooperation to occur in order to reduce the cost of the external audit (see Brody 2012). The cooperation could therefore result in a win-win situation in which the audit firm could gain competitive advantages by responding positively to the client's expectations (Broberg et al. 2013).

Focusing on cost reduction and related efficiency gains might risk compromising the audit quality. Respondent EA4 mentioned that time saving often leads to more client orientation and a stronger focus on the client's needs. This may indicate a shift of focus from audit quality to client satisfaction/orientation, as was also found by Duska 
(2005) and Broberg et al. (2013), who report that gaining competitive advantage by reducing audit fees, plus greater customer and market orientation, have become a common discourse in the audit industry.

Reducing the time spent on an audit could also result from pressure exerted by the audit firm (Broberg et al. 2013). Audit firms allocate a certain amount of time for audit engagements, which may result in pressure that influences how EAs perform their tasks and, in turn, could compromise audit quality (Broberg et al. 2017; Gundry and Liyanarachchi 2007; Svanberg and Öhman 2013). However, our respondents did not explicitly mention time pressure as a factor pushing them towards cooperation. According to EA4:

Assessment that I have too many clients or that I do not have enough time really has nothing to do with IAF, so to speak. But if I feel I do not have time and have too many engagements, then I cannot say, 'Oh, what a relief that there is an IAF, then I do not need to work as much.' [It does not work like that, and if it does then something is wrong.]'

Corroborating previous findings (Abbott et al. 2012; Pizzini et al. 2015; Lin et al. 2011), EA1 asserted that there might be a possible audit quality gain due to cooperation with the IA, because of the IA bringing 'insider' information to the table. Additionally, some respondents pointed out that EAs and IAs specializing in different areas can supplement each other in the audit work. One respondent went as far as to claim that he is more comfortable working with more experienced IAs, showing that experience matters in the cooperation (see Brody 2012).

When discussing the negative aspects of cooperation, our respondents evoked the issue of putting too much focus on the auditee and its needs at the expense of their independence, which is in line with Jeppesen (1998), who claimed that EAs' independence could be compromised if they act in the interest of the auditees. One of our respondents (EA8) seemed to be aware of this risk, commenting that:

[The auditee has expectations] that one should use the internal audit, but when they are not that competent and you cannot really use it, it can become a bit tricky. [...] It will not always be effective, but still one is going to use the work that fundamentally cannot be properly used.

This quote is in line with the findings by Desai et al. (2017) arguing that EAs may use the work of IAs even if doing so is unwarranted. Most EAs perceived their clients (auditees) with IAFs to have some expectations about cooperation. One respondent mentioned that focusing on the auditee view and overusing IAFs' work could threaten EAs' independence. The EA might disregard audit quality and prioritize client wishes/satisfaction. If an EA uses an IA's work, even if doing so will have several negative effects, then audit quality can be compromised.

All these findings indicate that self-interest could be embedded in the decision to cooperate, which can be related to the agency problem. EAs may seek to maximize their own benefit and fail to consider the good of the wider public and society (see Jensen and Meckling 1976; Ross 1973), which in turn could adversely affect the quality of the external audit. 


\subsubsection{Compromise of EAs' independence and professionalism?}

Our findings indicate that all EAs feel invested with great responsibility and that the maintenance of their legitimacy relies heavily on their ability to perform an independent audit, which is in line with the findings of previous studies (Carrington 2010; Duska 2005; Jeppesen 1998). In line with Baker and Hayes (1995), the responding EAs claimed that they have a responsibility not only towards the auditee but also towards the users and all stakeholders. In addition, our respondents agreed with Knechel et al. (2013), Francis (2011) and Grey (1998), claiming that professionals possess specific knowledge they require to perform their work.

Still, respondents EA4 and EA5 discussed the risk that the EA could come to a wrong conclusion and rely on the work of an IAF that is of poor quality. Further, EA8 mentioned that there is the risk that an EA could consciously choose to use work of poor quality. Thus, the quality of the external audit could be compromised. One EA argued that ISA 610 is clear, and as long as it is followed, the EA's independence and professionalism would not be affected. However, we maintain that there might be a tension between EAs' interest in cooperating and their responsibility towards the public. Taking into account the narratives of the respondents and the work tasks and the cooperation aspects they told us about, our own opinion is that a threat to their independence, while not acute, nevertheless exists.

In addition, one EA stated that the audit firm he was working in had opinions on the cooperation between IAs and EAs, indicating that such cooperation is perceived as sensitive and is being problematized at the firm level. At the same time, some EAs argued that the users of the external audit might not know that there could be cooperation between EAs and IAs because such information is not disclosed in any external reports. If the public is not aware of the cooperation, then it is not in a position to question it. An EA could therefore continue to act in self-interest even though the external audit could be perceived by users as having been prepared in an independent and professional way.

In sum, the findings of the qualitative part of this study resonate well with the elements of the theoretical framework presented in Fig. 1 and are also aligned with the results obtained in the quantitative part as explained in the following sub-sections.

\subsection{Research method: quantitative study}

The data were collected in April 2017 via an electronic survey sent to 2901 authorized and approved auditors that are members of FAR (Swedish Association of Certified Public Accountants). We received 41 usable responses; this is a low response rate, which might be due to the timing of the survey, in that April is the busiest month for EAs because most audited reports are due in May. In order to check for respondent bias, an explorative factor analysis has been performed on all questions in the questionnaire revealing an eight-factor structure with the largest factor representing 33\% of the eigenvalues variance. The questionnaire consisted of three blocks of questions, where Block 1 represented factual aspects, and Blocks 2 and 3 explored perceptual aspects of cooperation and the outcomes. 
Block 1: Individual/Firm characteristics, contained questions on auditors' Gender, Age, Professional tenure, Tenure as an authorized auditor, Partner or not, Big 4 or not.

Block 2 consisted of questions related to EAs' perception of interaction with IAs. The lead question asked: "To what extent are the following aspects important in your decision to use the work of the internal auditor?" The respondents were then asked on a 7-point Likert scale $(1=$ Not important and $7=$ Very important $)$ to respond to 14 different aspects (see Table 2). These aspects were inspired by the results and analysis of the qualitative study of this paper.

Block 3 consisted of questions related to EAs' perception of the outcomes of cooperation with IAs. The lead question asked: "To what extent does cooperation with an internal auditor influence the following?" The respondents were then asked on a 7-point Likert scale $(1=$ Not at all and $7=$ To a great extent) to react to four different aspects: Your independence, Your professional judgment, Your gatekeeping role, Your efficiency. These aspects in particular were included in the survey given the aim of the study. The data were explored by means of descriptive statistics, spearman correlation matrix, principal component analysis and multiple linear regression analysis (See "Appendix 2").

Given that dependent and independent variables were reported by single respondents, we used Harman's single-factor test to check for common method bias (Podsakoff et al. 2003). All independent and dependent variables were included in one unrelated factor analysis. The results indicated that the data had a multiple factor structure and limited common method bias.

\subsection{Results and analysis: quantitative study}

\subsubsection{Descriptive statistics}

Concerning Block 1, Table 2 shows that $24 \%$ of our respondents were women, the average professional tenure was approximately 23 years, while the average tenure as authorized auditors was approximately 17 years. Our average respondent was approximately 49 years old, $60 \%$ of the respondents were partners, and $50 \%$ of our sample consisted of auditors employed in Big 4 audit firms. Although our sample is small, the characteristics of our respondents do not significantly differ from the total population of Swedish auditors as reported in Broberg et al. (2018), apart from over-representation of the partners in our sample.

In relation to Block 2, one can observe that IA's professionalism and IA's competence have the highest mean values and are deemed by the responding EAs to be the most important aspects in the decision to use the work of the IAs. These findings resonate well with the findings of the qualitative part of the study, where respondents were in agreement that professionalism and competence are important starting points in the initiation of cooperation as well as its satisfactory continuation (cf. Brody 2012; Pike et al. 2016; Desai et al. 2017). IA's staff size, tenure at the client firm, and work experience with IAs at another firm together with the inaccuracy reduction were deemed least important in the cooperation decision. The findings related to the IA and the firm are 


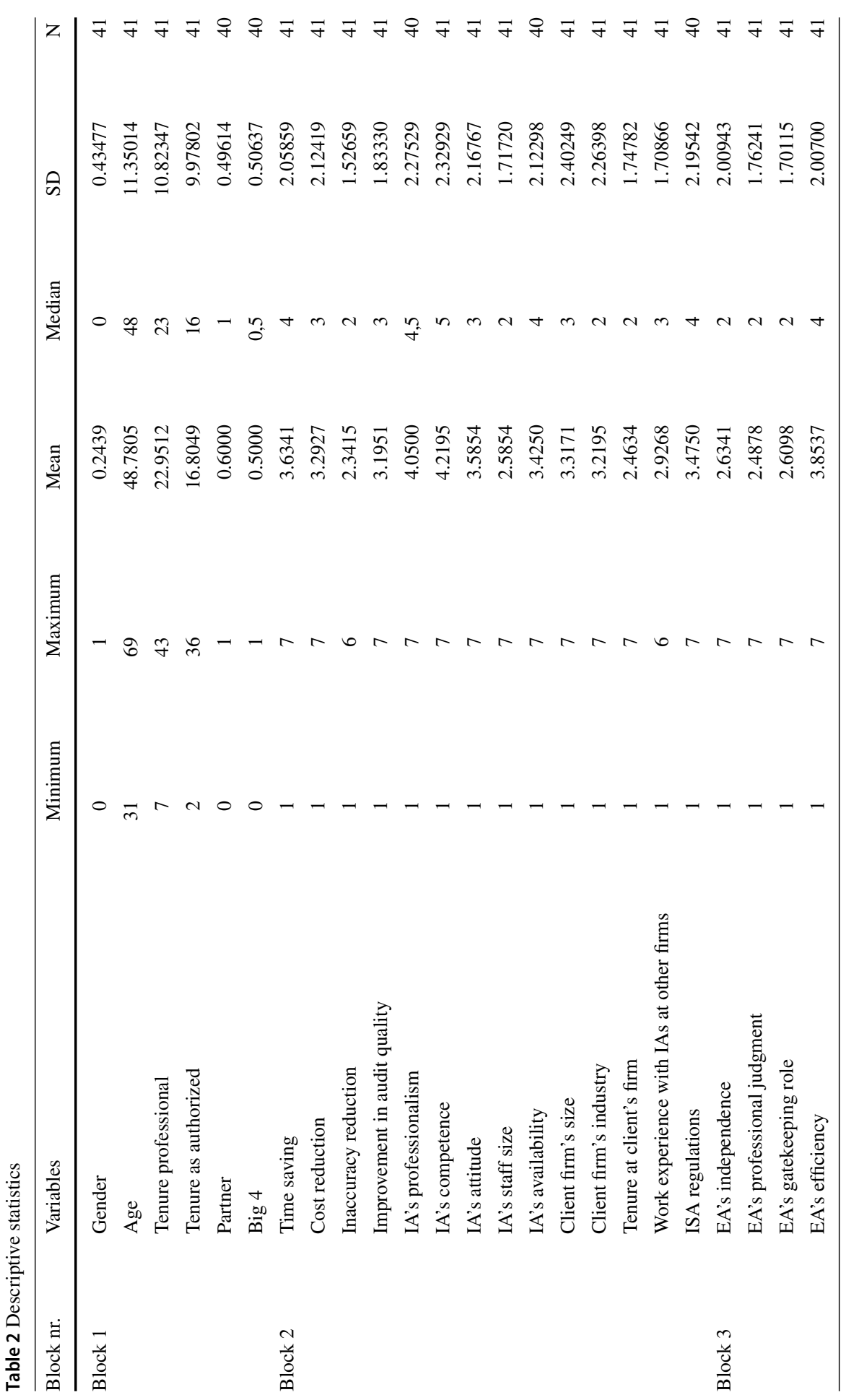


aligned with the findings of the qualitative study where however these findings were not as evident, which was also the case when it comes to the work experience with IAs. The latter could be explained by potential rarity of such a situation and thus EAs' lack of exposure to it. The lower ranking of inaccuracy reduction could potentially be related to EAs' confidence as well as overconfidence in performing audit assignments (cf. Hardies et al. 2011) as well as potential bias in answering this question due to the desire to maintain the status of the profession. The remaining aspects that had mean values between 3.19 and 3.63 were related to efficiency aspects (Time saving and Cost reduction), IA characteristics (IA attitude and IA availability), firm characteristics (Client firm's size and Client firm industry) as well as regulatory (ISA regulations) and audit-quality-related aspects (Improvement in audit quality). These aspects were quite evident in the qualitative part of the study and resonate well with the findings in previous literature (cf. Suwaidan and Qasim 2010; Brody 2012; Al-Twaijry et al. 2004).

Concerning Block 3, EA's efficiency gain stood out as the most important perceived outcome of the cooperation between EA and IA, which was also highlighted in the qualitative part of this study and has generated a lot of attention in past research (cf. Brody 2012). Relatively low means of the other three aspects were reflected in the interview-based findings, in that the EAs de-emphasized IAs' cooperation influence on their independence, professional judgment and gatekeeping role. This could potentially represent both the assertion and gestalt of the professional discretion but also the EAs' unwillingness to recognize potential risk associated with cooperating with IAs.

\subsubsection{Correlation matrix}

Given the limited number of observations and the number of variables that are not normally distributed, we have explored our data by means of Spearman Correlation (Table 3). From Table 3 we can observe that all the aspects in Block 2 are significantly positively correlated with EA's efficiency. Inaccuracy reduction appears to highly positively correlate with Improvement in audit quality as well as Tenure at client's firm, and has a weakly negative significant correlation with IA's professionalism. EA's professional judgment has a significant positive relationship with Tenure at client's firm and has weakly significant negative correlation with Cost reduction, Client's firm industry and Work experience with IAs at other firms. Finally, EA's independence appears to have a weakly significant positive relation with Cost reduction, Tenure at client's firm and ISA regulations, and weakly significant negative relation with IA's competence and Work experience with IAs at other firms. The bivariate relations here provide just some indications of the relationships between the reason for working with IAs and EAs' perceived outcomes of this cooperation. In order to explore what might be driving the EAs' perceptions, we perform the multiple linear regression analysis. Yet, due to the limited sample, we explore reasons for working with the IAs by the means of a Principle Component Analysis (PCA). 


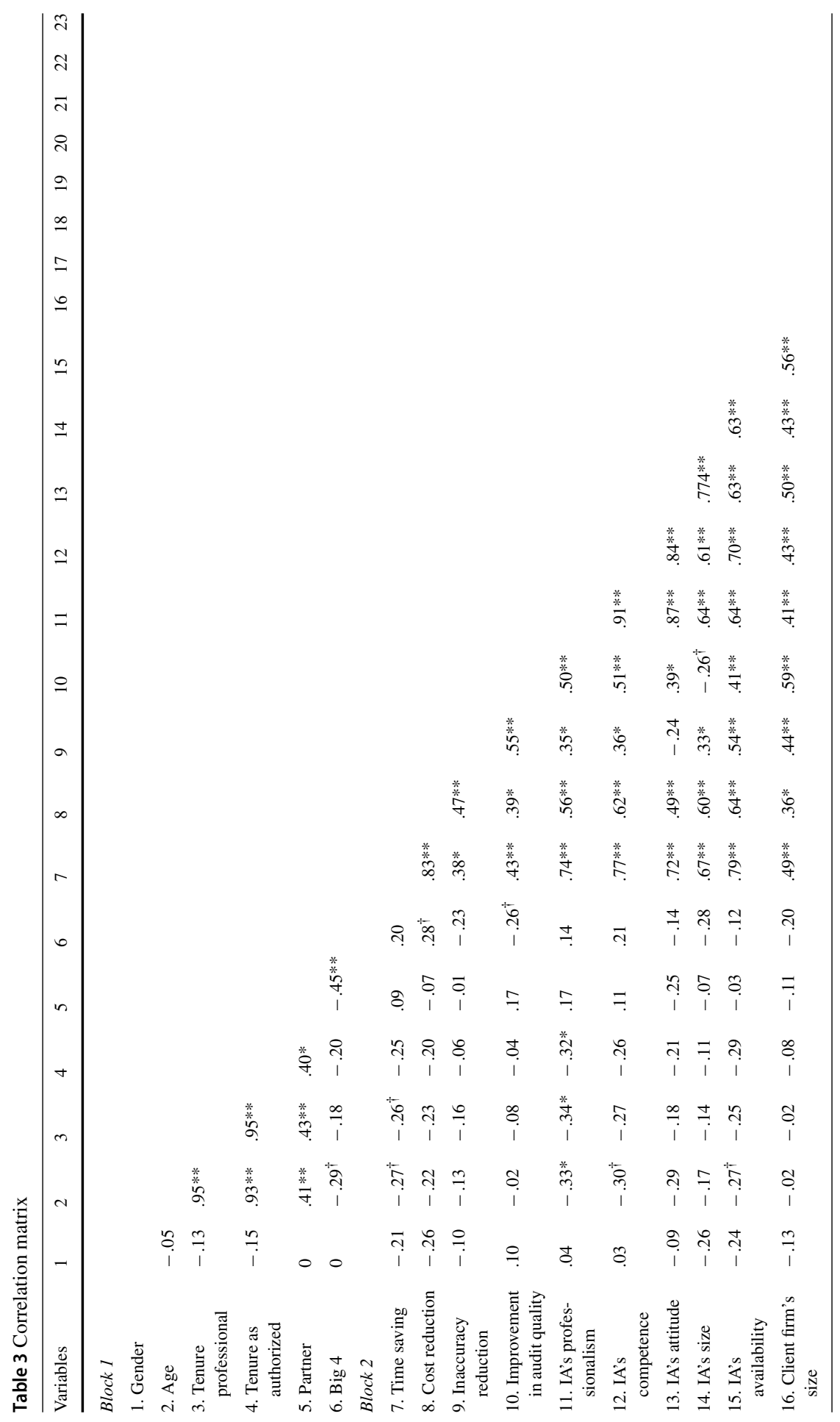




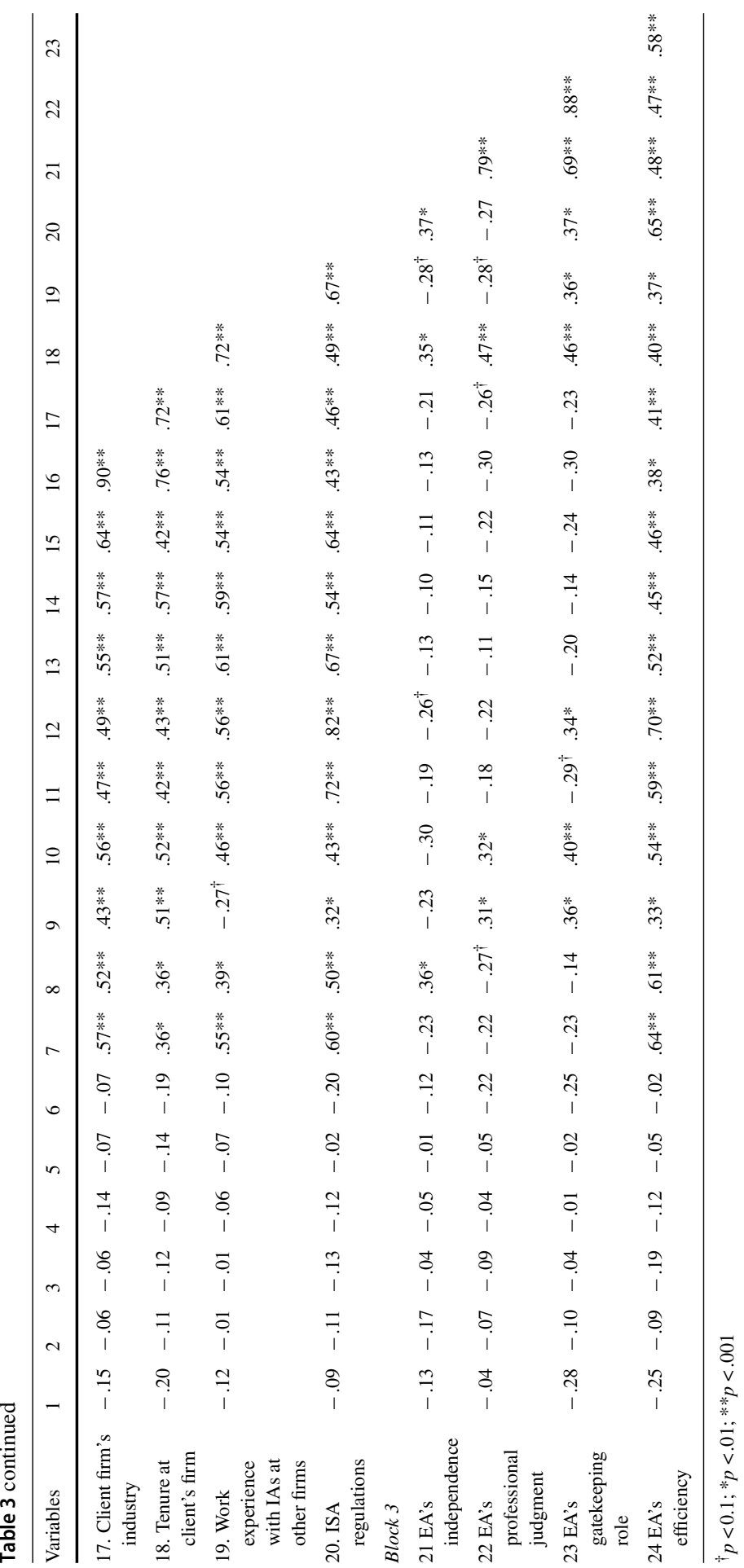


Table 4 Varimax rotated component matrix

\begin{tabular}{llll}
\hline Variables & $\begin{array}{l}\text { IA's characteristics } \\
\text { and efficiency }\end{array}$ & $\begin{array}{l}\text { Firm characteristics } \\
\text { and AQ }\end{array}$ & $\begin{array}{l}\text { Efficiency and } \\
\text { AQ }\end{array}$ \\
\hline IA's attitude & 0.882 & & \\
IA's competence & 0.855 & & 0.498 \\
IA's professionalism & 0.844 & & \\
Time saving & 0.785 & & \\
ISA regulations & 0.775 & & 0.532 \\
IA's size & 0.756 & 0.554 & \\
IA's availability & 0.670 & 0.849 & \\
Work experience with & 0.627 & 0.827 & \\
$\quad$ IAs at other firms & & 0.755 & 0.489 \\
Tenure at client's firm & & 0.603 & 0.810 \\
Client firm's size & & & 0.646 \\
Client firm's industry & & & \\
Improvement in audit & & & \\
$\quad$ quality & & & \\
Inaccuracy reduction & & & \\
Cost reduction & 0.581 &
\end{tabular}

\subsubsection{Factor analysis}

We have performed the PCA on all the questions in Block 2. We checked the correlations between the variables (which only in 3 cases did not exceed .3), sampling adequacy (MSA, which was high) and Kaiser-Meyer-Olkin (KMO, above 0.7). The eigenvalues and screen plot indicated that three components should be used (all communality values were preferred 0.4 ). From Table 4: Varimax rotated component matrix we can observe that a number of factors have a crossloading, that is, Time saving, IA's availability, Work experience with IAs at other firms, Improvement in audit quality and Cost reduction. Based on our interpretation of the components within each factor we have called Factor 1: IA's Characteristics and efficiency; Factor 2: Firm characteristics and Audit Quality (AQ) and Factor 3: Efficiency and external audit quality (AQ). That is how the respondents in our sample appear to perceive and relate different reasons for working with IAs.

\subsubsection{Multiple regression analysis}

To explore our data further, we perform a multiple linear regression analysis. Given the limitation of our sample, we only include the three factor scores as well as two aspects from Block 1, namely the Big 4 and the Professional tenure of the responding auditor, given that both have been shown to relate to the choice of using IAs in previous research (e.g. Soh and Martinov-Bennie 2011; Mohamed et al. 2012). We perform four regression tests, one for each outcome variable in Block 3. Our testing indicated that only one out of four regression models was significant, namely, the model with EAs' 
Table 5 Multiple regression analysis

$\dagger p<0.1 ; * p<.01 ; * * p<.001$

\begin{tabular}{lcc}
\hline Variables & \multicolumn{2}{l}{ EA's efficiency } \\
\cline { 2 - 3 } & $\mathrm{B}$ & Std.E \\
\hline $\begin{array}{l}\text { IA's characteristics } \\
\text { and efficiency }\end{array}$ & $1.154^{* *}$ & .229 \\
$\begin{array}{l}\text { Firm characteristics } \\
\text { and AQ }\end{array}$ & $.577 \dagger$ & .213 \\
Efficiency and AQ & $.836^{* *}$ & .208 \\
Tenure professional & -.002 & .020 \\
Big 4 & .042 & .481 \\
Constant & $3.853^{* *}$ & .567 \\
F-value & $10.767^{* *}$ & \\
Adj. $\mathrm{R}^{2}$ & .576 & \\
VIF value, highest & 1.442 & \\
\hline
\end{tabular}

efficiency as a dependent variable. This regression is reported in Table 5, showing that it is IAs' characteristics and efficiency that are primarily associated with it, as well as Efficiency and AQ considerations that are significantly correlated with EAs' perceived efficiency associated with the use of IAs' work.

The findings reported in this regression model resonate well with those of the qualitative part of this study showing that EA's efficiency gain is an important outcome of cooperation with an IA. These findings also reflect EAs' interview-deduced reflections as to what might be triggering this view. Similar to the qualitative part, the quantitative findings suggest that it is IAs' characteristics, audit quality improvements and ideas related to efficiency that are important parts of the decision to use IAs' work and are related to the perceived efficiency gains on the part of EA. Yet what the quantitative study shows is a more nuanced picture as to how the triggers of that perception are aligned with each other and their relation to the EAs' efficiency perception. It appears that decisions related to efficiency are highly intertwined with decisions related to IA characteristics and improvements in audit quality. Thus it might indicate that when a decision to cooperate with IAs is made, the EAs consider the IA's characteristics and efficiency gains simultaneously and consider them to be closely associated with each other, which in turn influences EAs' perceived efficiency (cf. Endaya and Hanefah 2016). The same applies to the interrelation between efficiency and improved audit quality and their subsequent relation to EAs' perceived efficiency, which has also been highlighted in the previous literature (Abbott et al. 2012).

Regression models with EA's independence, EA's professional judgment and EA's gatekeeping role as dependent variables were found to be not significant, thus indicating that different EAs do not consider the IAs' related factors to be associated with these specific outcomes. There could be several explanations to these non-findings. First, EAs perceive these three outcome aspects in a very homogeneous way, and the strength of embeddedness in the profession makes the respondents uniform in their answers, thus showing a low degree of variation (cf. Emby 1994; Broberg 2013). This explanation finds its support in other quantitative studies on auditors and difficulties with getting variability in answers given the homogeneity of professional identity and 
values in this profession (cf. Umans et al. 2016). Another possible explanation may lie in the single-item measures of the complex concepts that do not allow the respondents to assess the full meaning of the terms (cf. Fuchs and Diamantopoulos 2009). Here the qualitative part of the study provides a better-articulated insight into how EAs reason about their independence, professional judgment and gatekeeping role and how these relate to their decision to enter into cooperation with an IA. Finally, non-findings might signal EAs' caution in answering questions related to them as individuals rather than as members of the profession, something that the qualitative part of the study has captured by allowing the respondents to make a choice of answering for themselves or for the role/profession.

Overall, the findings of the quantitative investigation highlight the complexity of the EAs' decision-making concerning reliance on the IAs' work, yet they provide a more nuanced understanding of the importance and interrelation of the triggers of these decisions.

\section{Discussion and conclusions}

The purpose of this study is to explore how EAs experience their decision to rely on IAs' work and to understand how exposure to such interaction relates to EAs' perceived independence, professionalism and experiences with audit quality.

The findings seem to suggest that EAs tend to make strategic decisions (see SteptoeWarren et al. 2011) when cooperating with IAs, and the efficiency improvements stemming from the cooperation (Brody 2012) is an aspect respondents in both qualitative and quantitative parts of the study consider to be important. Efficiency gains were deemed beneficial for all parties involved (i.e. EAs and auditees), even though some EAs appeared to prioritize their self-interest (see Etzioni 2014) over the interests of the auditees and the stakeholders. When EAs seem to act in their own interest (see Jensen and Meckling 1976; Ross 1973), there is a risk that they do not consider the responsibility and duty of their role, which collides with the assumption that EAs should prioritize the interests of others (Chrystelle 2006). The misalignment between the EAs' self-interest and their professional responsibility might imply that there is an agency problem (see Duska 2005) involved in the cooperation (between EAs and IAs), which could be a dangerous path if applied in the audit industry at large.

In addition, the qualitative analysis suggested that EAs did not experience time pressure imposed by the firm that employs them, yet the aspect of being efficient in general still contributed to the overall pressure they experienced in the audit process. Likewise, the EAs' own independence and professionalism appeared to be important in their role as auditors, and most of the EAs appeared not to think that their ability to keep their objectivity and professional judgment was severely compromised when cooperating with IAs. Despite this, our findings might suggest that in some circumstances there could be an acceptance of a certain degree of lower audit quality among EAs when cooperating with IAs. Our findings might also indicate that the EAs do not seem to perceive cooperation in itself as a major dilemma. However, some EAs did mention that there could be a risk regarding the audit quality when relying on the work 
of IAs whose professionalism and independence appear to be questioned by EAs. This shows that EAs may still use IAs' work even if it is not optimal (Desai et al. 2017).

An aspect that emerged from the qualitative analysis is that there might be pressure from the auditee to cooperate, that there is an expectation that cooperation will take place, as argued in the literature (see Brody 2012). Even if the EAs seemed to some degree to consider the interest of the auditee, they pointed out that the evaluation of the objectivity, competence and quality of the IAs was an important aspect in determining how the cooperation could work (see Pike et al. 2016; Desai et al. 2017). Another aspect that emerged was the distinction that EAs appeared to be making between outsourced IAFs and in-house IAFs. EAs considered outsourced IAFs to be more independent, competent and trustworthy, and hence the EAs were more inclined to rely on their work. That appears to be in line with the findings of Chen et al. (2017) and Glover et al. (2008), who found that outsourced IAFs are held in higher esteem by EAs than the in-house ones. Yet there might be some issues of considering outsourced IAs as internal actors, and this might explain why EAs may assess their objectivity to be greater than that of in-house IAs.

Finally, the qualitative part of our study indicated that the type and the length of cooperation including communication, trust and personal chemistry were not perceived to be of major importance by the EAs in their decision to cooperate with IAs. This might suggest a rather high degree of rationality on the part of EAs (see Edwards 1954; Jonassen 2012) in their decision making when cooperating with IAs. It appears that professionalism might prevail over emotions, experiences and personal identity in the cooperation between the two parties.

The quantitative part of our paper provides some insights into the motivation to work with IAs, and it also provides some hints as to how these motivational aspects relate to EAs' perception of the outcomes of cooperation with IAs. In relation to motivation, the EAs in our sample appear to base their decision to cooperate on three aspects, namely, IAs' characteristics and efficiency gained by EAs, client firm characteristics and quality of the external audit, as well as the quality of external audit combined with the efficiency gains. Our results might further indicate that it is the first and third motivators that are positively associated with the EAs' perception of efficiency gains. These findings resonate well with the findings of the qualitative part of the paper, where we found that EAs are aware of the IAs' qualities as well as efficiency-related aspects.

The findings of this paper might be indicative for both regulators and standard setters, in that they open up the discussion on a dilemma in the EAs' profession. The paper also touches upon the role and responsibility of the IAs (at least from the EAs' perspective) and suggests that one could consider strengthening the legitimacy and the role of the IA function (for example, by offering them professional status through authorization), which could in turn be associated with the quality of the IAs' work. One could suggest that if EAs use that work, not only would there be efficiency gains due to avoidance of work duplication, but external audit quality could also be enhanced and protected.

The findings might also be useful for EAs in their consideration of the different aspects of cooperation with IAs. More specifically, there are indications that multiple 
aspects might need to be simultaneously taken into account when deciding about cooperation.

In exploring the processes through which decisions are being made as well as perceived consequences of these decisions, our study contributes with an insight that EAs' perceptions of IAs' qualities are tightly intertwined with the perception of perceived efficiency gains. We further find that EAs possess some degree of efficiency expectations in deciding to cooperate with IAs, which might be misaligned with their overall obligation to maintain their professionalism and independence.

\subsection{Limitations and future research directions}

There are a number of limitations in this study. First, the small number of observations in both the qualitative and quantitative parts of the study does not allow for generalizing to the population, and only allows for cautious interpretation of the results. Second, the validity of the results might represent an issue due to the strong focus on financial institutions as audit clients, which further reduces the generalizability of the results. Third, the results of this study might not be transferable to other settings, given the high social trust in the Swedish society, which is the context of this study. Fourth, being an EA perception-based study, our paper lacks the voices from the other side, that is, those of IAs, and it thus represents a relatively one-sided view on the cooperation between the parties. Fifth, the interview guide used for the qualitative study included broad questions that do not always fully correspond to the exact concepts in the theoretical framework (Fig. 1). Yet, this was a conscious choice given the explorative nature of the study and the aim of gaining a broader understanding of the EAs' experiences. Finally, both the qualitative and quantitative parts of the study are experience and perception based. This has some implications for the trustworthiness of this study, even though a number of remedies were used in employing both methods.

Future research may consider audit firms other than the Big 4, or a comparison between the Big 4 and the other audit firms, in order to investigate whether there is a difference in the risk propensity concerning the audit quality. A study from another perspective, such as the perspectives of IAs, the auditees or the stakeholders, could supplement the findings of the present study. This study indicates that, in their work, EAs might act in self-interest, and it would be interesting to investigate whether there are differences in the degree of self-interest depending on different demographic characteristics. Finally, a more comprehensive qualitative and quantitative investigation could explore the underlying processes that occur before and during EAs' and IAs' work and the degree to which these processes are related to EAs' professional role and independence.

Open Access This article is distributed under the terms of the Creative Commons Attribution 4.0 International License (http://creativecommons.org/licenses/by/4.0/), which permits unrestricted use, distribution, and reproduction in any medium, provided you give appropriate credit to the original author(s) and the source, provide a link to the Creative Commons license, and indicate if changes were made. 


\section{Appendix 1: Interview guide}

Introductory questions:

Tell us about yourself. (name, profession, place of work, experience, education)

The EA role:

Describe briefly how you as an auditor see your role and your responsibilities. (independence aspects, client relations, stakeholder focus, societal needs)

Cooperation with IAs:

How many of your clients have an internal audit function? (number and proportion of the total number of clients)

How many clients do you cooperate with, and how was cooperation initiated? (planned/spontaneous)

How was the relationship initiated? Describe the process. (you yourself, your employer, internal auditors, the auditee, ISA)

How was your work situation related to the decision to cooperate. (number of clients, time pressure, etc.)

What characterizes your cooperation/communication with IA? (frequency, the medium)

How does the nature of your communication affect your trust in the internal auditor?

What is your opinion about IA work?

Do the internal auditors perform any work under your guidance as external auditor?

To what extent is the information/work of IA useful? How do you use it?

Do you feel that the length/type of cooperation influences your use of IA work? If so, in what way?

Are there any guidelines/regulations for how you as an auditor should consider the internal auditing (formal/informal, from the accounting firm or established between you and the internal auditors)?

How do you evaluate the internal auditor's objectivity and competence?

Does the evaluation of the internal audit function and the internal auditors lead to more or less work for you in the audit process?

Does the length or type of cooperation influence how you evaluate the internal auditor's work? In what way?

How important is personal chemistry when cooperating with internal auditors? Why?

Overall, what positive effects do you think the cooperation between you and IAs entails?

Overall, what negative effects do you think the cooperation between you and IAs entails?

Do you consider the positive and negative aspects of cooperation when deciding how to perform your audit tasks?

Does the cooperation have any effects on the audit fee and audit quality? How do you consider these effects?

When cooperating with internal auditors and making use of their work, how conscious are you about your professional judgment and independence? Are they compromised? How? 
Are you aware of any stakeholders' specific opinions regarding cooperation between external and internal auditors?

Is there anything you would like to add about what we have talked about?

\title{
Appendix 2: Questionnaire
}

\author{
Block 1: General Questions \\ 1. I am a woman/man. \\ 2. I was born (year). \\ 3. I started working in auditing in (year). \\ 4. I became an authorized auditor in (year). \\ 5. Are you a partner in your firm? (Y/N)
}

Block 2: Interaction with internal auditor (IA)

To what extent are the following aspects important in your decision to use the work of the internal auditor (IA)? $1=$ not important and $7=$ very important (All questions were answered on a 7-point Likert scale.)
6. Time saving
7. Cost reduction
8. Inaccuracy reduction
9. Improvement in audit quality
10. IA's professionalism
11. IA's competence
12. IA's attitude
13. IA's staff size
14. IA's availability
15. Client firm's size
16. Client firm's industry
17. Tenure at client's firm
18. Work experience with IAs at other firm
19. ISA stipulations

\section{Block 3: Outcomes}

To what extent does cooperation with an internal auditor influence the following? $1=$ Not at all and $7=$ To a great extent

20. Your independence

21. Your professional judgment

22. Your gatekeeping role

23. Your efficiency 


\section{References}

Abbott, L., Parker, S., \& Peters, G. F. (2012). Internal audit assistance and external audit timeliness. Auditing: A Journal of Practice \& Theory, 31(4), 3-20.

Allegrini, M., D’Onza, G., Paape, L., Melville, R., \& Sarens, G. (2006). The European literature review on internal auditing. Managerial Auditing Journal, 21(8), 845-853.

Al-Twaijry, A. A. M., Brierley, J. A., \& Gwilliam, D. R. (2004). An examination of the relationship between internal and external audit in the Saudi Arabian corporate sector. Managerial Auditing Journal, 19(7), 929-944.

Arena, M., \& Azzone, G. (2009). Identifying organizational drivers of internal audit effectiveness. International Journal of Auditing, 13(1), 43-60.

Arnold, D. F., Sr., Dorminey, J. W., Neidermeyer, A. A., \& Neidermeyer, P. E. (2013). Internal and external auditor ethical decision-making. Managerial Auditing Journal, 28(4), 300-322.

Arya, A., \& Glover, J. (2014). Auditor independence revisited. Journal of Accounting, Auditing \& Finance, 29(2), 188-198.

Bachmann, R., \& Inkpen, A. (2011). Understanding institutional-based trust building processes in interorganizational relationships. Organization Studies, 32(2), 281-301.

Baker, R., \& Hayes, R. (1995). The Negative effect of an accounting standard on employee welfare: The CASE of McDonnell Douglas Corporation and FASB 106. Accounting, Auditing, and Accountability Journal, 8(3), 12-33.

Bame-Aldred, C. W., Brandon, D. M., Messier, W. F., Rittenberg, L. E., \& Stefaniak, C. M. (2013). A summary of research on external auditor reliance on the internal audit function. Auditing: A Journal of Practice \& Theory, 32(1), 251-286.

Broberg, P. (2013). The auditor at work: A study of auditor practice in Big 4 audit firms (Doctoral dissertation, Department of Business Administration, School of Economics and Management, Lund University).

Broberg, P., Tagesson, T., Argento, D., Gyllengahm, N., \& Mårtensson, O. (2017). Explaining the influence of time budget pressure on audit quality in Sweden. Journal of Management and Governance, 21(3), 331-350.

Broberg, P., Umans, T., \& Gerlofstig, C. (2013). Balance between auditing and marketing. Journal of International Accounting, Auditing \& Taxation, 22(1), 57-70.

Broberg, P., Umans, T., Skog, P., \& Theodorsson, E. (2018). Auditors' professional and organizational identities and commercialization in audit firms. Accounting, Auditing \& Accountability Journal, 31(2), 374-399.

Brody, R. G. (2012). External auditors' willingness to rely on the work of internal auditors: The influence of work style and barriers to cooperation. Advances in Accounting, 28(1), 11-21.

Carrington, T. (2010). An analysis of the demands on a sufficient audit: Professional appearance is what counts! Critical Perspectives on Accounting, 21(8), 669-682.

Chen, L. H., Chung, H. H., Peters, G. F., \& Wynn, J. P. (2017). Does incentive-based compensation for chief internal auditors impact objectivity? An external audit risk perspective. Auditing: A Journal of Practice \& Theory, 36(2), 21-43.

Chrystelle, R. (2006). Why an auditor cannot be competent and independent: A French case study. The European Accounting Review, 15(2), 153-179.

Delbufalo, E. (2012). Outcomes of inter-organizational trust in supply chain relationships: A systematic literature review and a meta-analysis of the empirical evidence. Supply Chain Management: An International Journal, 17(4), 377-402.

Denscombe, M. (2009). Forskningshandboken: för småskaliga forskningsprojekt inom samhällsvetenskaperna. Lund: Studentlitteratur AB.

Desai, R., Desai, V., Libby, T., \& Srivastava, R. P. (2017). External auditors' evaluation of the internal audit function: An empirical investigation. International Journal of Accounting Information Systems, 24, $1-14$.

Duska, R. (2005). The Good auditor-Skeptic or wealth accumulator? Ethical lessons learned from the Arthur Andersen debacle. Journal of Business Ethics, 57(1), 17-29. 
Edwards, W. (1954). The theory of decision making. Psychological Bulletin, 51(4), 380-417.

Emby, C. (1994). Framing and presentation mode effects in professional judgment: Auditors' internal control judgments and substantive testing decisions. Auditing: A Journal of Theory and Practice, 13(1), 102-115.

Endaya, K. A., \& Hanefah, M. M. (2016). Internal auditor characteristics, internal audit effectiveness, and moderating effect of senior management. Journal of Economic and Administrative Sciences, 32(2), 160-176.

Etzioni, A. (2014). Humble decision-making theory. Public Management Review, 16(5), 611-619.

FAR. (2013). Praktisksamverkan mellan intern- och externrevisorer. http://www.far.se/PageFiles/6820/ SAMVERKANINTERNOCHEXTERNREV.PDF. Accessed 14 April 2014.

Felix, W. L., Gramling, A. A., \& Maletta, M. (2001). The contribution of internal audit as a determinant of external audit fees and factors influencing this contribution. Journal of Accounting Research, 39(3), 513-534.

Francis, J. R. (2011). A framework for understanding and researching audit quality. Auditing: A Journal of Practice \& Theory, 30(2), 125-152.

Fuchs, C., \& Diamantopoulos, A. (2009). Using single-item measures for construct measurement in management research: Conceptual issues and application guidelines. Die Betriebswirtschaft, 69(2), 195-210.

Glover, S. M., Prawitt, D. F., \& Wood, D. A. (2008). Internal audit sourcing arrangement and the external auditor's reliance decision. Contemporary Accounting Research, 25(1), 193-213.

Grey, C. (1998). On being a professional in a 'Big Six' firm. Accounting, Organizations and Society, 23(5-6), 569-587.

Guest, G., Bunce, A., \& Johnson, L. (2006). How many interviews are enough? An experiment with data saturation and variability. Field Methods, 18(1), 59-82.

Gundry, C. L., \& Liyanarachchi, A. G. (2007). Time budget pressure, auditors personality type, and the incidence of reduced audit quality practices. Pacific Accounting Review, 19(2), 125-152.

Håkansson, P. \& Johansson, A. (2014). To cooperate with internal auditors or not. Is that a Dilemma for Swedish External Auditors? Master Thesis, Kristianstad University.

Hardies, K., Breesch, D., \& Branson, J. (2011). Male and female auditors' overconfidence. Managerial Auditing Journal, 27(1), 105-118.

Harvey, W. S. (2011). Strategies for conducting elite interviews. Qualitative Research, 11(4), 431-441.

IIA (2018a). CIA certification. https://global.theiia.org/certification/CIA-Certification/Pages/CIACertification.aspx. Accessed 24 September 2018.

IIA (2018b). Standards and guidance. https://global.theiia.org/standards-guidance/Pages/Standards-andGuidance-IPPF.aspx. Accessed 24 September 2018.

ISA 200. (2009). Overall objectives of the independent auditor and the conduct of an audit in accordance with international standards on auditing. International Standard on Auditing 200. http://www.ifac.org/ sites/default/files/downloads/a008-2010-iaasb-handbook-isa-200.pdf. Accessed 15 April 2014.

ISA 315. (2013). International standard on auditing (ISA) 315 Identifying and assessing the risks of material misstatement through understanding the entity and its environment. http://www.ifac.org/sites/default/ files/downloads/a017-2010-iaasb-handbook-isa-315.pdf. Accessed 15 April 2014.

ISA 610. (2013). International standard on auditing (ISA) 610 (revised 2013) Using the work of internal auditors and related conformity amendments, IFAC, ISBN: 978-1-60815-149-3. https://www. iaasb.org/system/files/publications/files/ISA-610-\%28Revised-2013\%29.pdf. Accessed 25 September 2018 .

Jensen, M. C., \& Meckling, W. H. (1976). Theory of the firm: Managerial behaviour, agency costs and ownership structure. Journal of Financial Economics, 3(4), 305-360.

Jeppesen, K. K. (1998). Reinventing auditing, redefining consulting and independence. European Accounting Review, 7(3), 517-539.

Jonassen, D. H. (2012). Designing for decision making. Educational Technology Research and Development, $60(2), 341-359$.

Knechel, W. R., Krishnan, G. V., Pevzner, M., Shefchik, L. B., \& Velury, U. K. (2013). Audit quality: Insights from the academic literature. Auditing: A Journal of Practice \& Theory, 32(1), 385-421.

Lin, S., Pizzini, M., Vargus, M., \& Bardhan, I. R. (2011). The role of the internal audit function in the disclosure of material weaknesses. The Accounting Review, 86(1), 287-323.

Mayer, R. C., Davis, J. H., \& Schoorman, F. D. (1995). An integrative model of organizational trust. Academy of Management Review, 20, 709-734. 
McNamara, M. S., \& Liyanarachchi, A. G. (2008). Time budget pressure and auditor dysfunctional behaviour within an occupational stress model. Accountancy Business and the Public Interest, 7(1), 1-43.

Mihret, D. G. (2014). How can we explain internal auditing? The inadequacy of agency theory and a labor process alternative. Critical Perspectives on Accounting, 25(8), 771-782.

Mihret, D. G., \& Admassu, M. A. (2011). Reliance of external auditors on internal audit work: A corporate governance perspective. International Business Research, 4(2), 67-79.

Mohamed, Z., Mat Zain, M., Subramaniam, N., Yusoff, W., \& Fadzilah, W. (2012). Internal audit attributes and external audit's reliance on internal audit: Implications for audit fees. International Journal of Auditing, 16(3), 268-285.

Morrill, C., \& Morrill, J. (2003). Internal auditors and the external audit: A transaction cost perspective. Managerial Auditing Journal, 18(6/7), 490-504.

Munro, L., \& Stewart, J. (2011). External auditors' reliance on internal auditing: Further evidence. Managerial Auditing Journal, 26(6), 464-481.

Pike, B. J., Chui, L., Martin, K. A., \& Olvera, R. M. (2016). External auditors' involvement in the internal audit function's work plan and subsequent reliance before and after a negative audit discovery. Auditing: A Journal of Practice \& Theory, 35(4), 159-173.

Pizzini, M., Lin, S., \& Ziegenfuss, D. E. (2015). The impact of internal audit function quality and contribution on audit delay. Auditing: A Journal of Practice \& Theory, 34(1), 25-58.

Podsakoff, M., Scott, B., MacKinzie, S. B., Podsakoff, N., \& Lee, J.-Y. (2003). Common method biases in behavioral research: A critical review of the literature and recommended remedies. Journal of Applied Psychology, 88, 879-903.

Ross, S. A. (1973). The economic theory of agency: The principal's problem. The American Economic Review, 63(2), 134-139.

Rothstein, B., \& Uslaner, E. M. (2005). All for all: Equality, corruption, and social trust. World Politics, $58(01), 41-72$.

Roussy, M., \& Brivot, M. (2016). Internal audit quality: A polysemous notion? Accounting, Auditing \& Accountability Journal, 29(5), 714-738.

Ryan, B., Scapens, R. W., \& Theobald, M. (2002). Research method and methodology in finance and accounting (2nd ed.). London: Cengage Learning.

SFS 2006:1228. Internrevisionsförordning. http://www.riksdagen.se/sv/Dokument-Lagar/Lagar/ Svenskforfattningssamling/Forordning-20061228-om-arbet_sfs-2006-1228/?bet=2006:1228. Accessed 14 April 2014.

Soh, D. S. B., \& Martinov-Bennie, N. (2011). The internal audit function: Perceptions of internal audit roles, effectiveness and evaluation. Managerial Auditing Journal, 26(7), 605-622.

Steptoe-Warren, G., Howat, D., \& Hume, I. (2011). Strategic thinking and decision making: Literature review. Journal of Strategy and Management, 4(3), 238-250.

Stewart, J., \& Subramaniam, N. (2010). Internal audit independence and objectivity: Emerging research opportunities. Managerial Auditing Journal, 25(4), 328-360.

Suwaidan, M. S., \& Qasim, A. (2010). External auditors' reliance on internal auditors and its impact on audit fees: An empirical investigation. Managerial Auditing Journal, 25(6), 509-525.

Svanberg, J., \& Öhman, P. (2013). Auditors' time pressure: Does ethical culture support audit quality? Managerial Auditing Journal, 28(7), 572-591.

Swanger, S. L., \& Chewning, E. G., Jr. (2001). The effect of internal audit outsourcing on financial analysts' perceptions of external auditor independence. Auditing A Journal of Practice \& Theory, 20(2), 115-129.

Swedish Corporate Governance Board. (2010). The Swedish corporate governance code. http://www. corporategovernanceboard.se/media/45322/svenskkodbolagsstyrn_2010_eng_korrigerad20110321. pdf. Accessed 14 April 2014.

Tagesson, T., \& Eriksson, O. (2011). What do auditors do? Obviously they do not scrutinise the accounting and reporting. Financial Accounting \& Management, 27(3), 272-285.

Thomas, A. B. (2004). Research skills: For management studies. New York: Routledge.

Thomas, E., \& Magilvy, J. K. (2011). Qualitative rigor or research validity in qualitative research. Journal for Specialists in Pediatric Nursing, 16(2), 151-155.

Tomkins, C. (2001). Interdependencies, trust and information in relationships, alliances and networks. Accounting, Organizations and Society, 26(2), 161-191. 
Umans, T., Broberg, P., Schmidt, M., Nilsson, S., \& Olsson, E. (2016). Feeling well by being together: Study of Swedish auditors. Work, 54(1), 79-86.

Vangen, S., \& Huxham, C. (2003). Nurturing collaborative relations: Building trust in interorganizational collaboration. The Journal of Applied Behavioral Science, 39(5), 5-31.

Publisher's Note Springer Nature remains neutral with regard to jurisdictional claims in published maps and institutional affiliations. 